\title{
Conhecimento científico, políticas públicas e regulação na área de saúde: um novo paradigma
}

\author{
Scientific knowledge, public policies and regulation in health care: a new paradigm
}

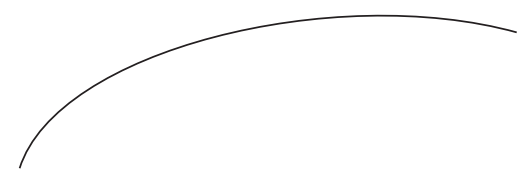

Há poucos meses, a Agência Nacional de Saúde Suplementar realizou um importante seminário denominado "Conhecimento científico como subsídio regulatório". O principal palestrante, professor Maurício Barreto, da Universidade Federal da Bahia, trouxe uma abordagem contemporânea e bastante oportuna sobre a produção acadêmica brasileira. Segundo ele, vem ocorrendo uma clara tendência de redução das atividades econômicas e sociais diretas do Estado, em paralelo à ampliação de políticas, legislação e normas regulatórias de uma série de parâmetros da vida social. É o que alguns autores chamam de Estado Regulatório ou Capitalismo Regulatório. Nesse contexto, consolida-se a noção de que as decisões devem ser tomadas com base em conhecimentos científicos. É o conceito de política baseada em evidência, do qual o Estado moderno se apropriou, com especial ênfase na área da saúde, tornando-se um crescente consumidor dos resultados da atividade científica. Dessa forma, as políticas públicas poderão ser mais efetivas para a população, com menos custos econômicos ou sociais.

Entende-se que se deva ampliar o componente científico, na expectativa de beneficiar a população, mas é fundamental pontuar que este é apenas um dos componentes do processo de elaboração de decisões no campo da saúde - parte dele, contudo, não é, e talvez jamais venha a ser cientificamente fundamentado.

Deve-se considerar, portanto, um dilema frequentemente vivenciado: em alguns momentos, faltam conhecimentos para que decisões sejam tomadas; em outros, embora existam conhecimentos suficientes, não há, por motivos diversos, a capacidade ou a vontade de tomá-las. A elaboração de políticas e outras atividades que exigem decisões em ambientes democráticos são processos complexos, que envolvem diversos interesses e atores, daí a necessidade de amplo debate sobre a adoção de instrumentos regulatórios.

No campo da saúde, quase nenhum aspecto escapa à regulação. Isto inclui pesquisa e desenvolvimento, produção de medicamentos e equipamentos, profissionais, unidades de saúde, seguros e toda uma rede heterogênea de atividades e serviços que envolvem esse setor. O ápice desse processo é o aparecimento das ditas agências reguladoras, cuja função seria balizar a circulação de tecnologias, serviços e capitais. Seu papel deveria ser conciliador, buscando universalizar o acesso aos serviços de saúde, melhorar sua qualidade, controlar custos e garantir segurança aos usuários. 
O avanço cada vez maior e mais rápido da tecnologia provoca um aumento nos custos, o que resulta na necessidade de fomentar seu uso racional. Na mesma linha de conduta, os riscos associados aos avanços tecnológicos devem ser cuidadosamente analisados e controlados, sem prejuízo tanto para a pesquisa científica como para os usuários do sistema de saúde.

O papel do conhecimento científico se modifica e se amplia. A inovação é essencial para atender às necessidades de uma sociedade em permanente transformação. E a regulação deve ser ágil e precisa para assegurar que o estado da arte do conhecimento científico chegue aos cidadãos sem prejuízo dessa dinâmica. Eis aí o novo paradigma da produção científica e o desafio maior do marco regulatório.

Encerra-se o ciclo da pesquisa fundamental, aquela que gera conhecimento sobre problemas de significância científica sem considerar as necessidades mais imediatas da sociedade. Inicia-se a etapa da pesquisa estratégica, que também gera conhecimento sobre problemas e necessidades específicas de saúde, mas apresenta resultados que podem proporcionar mudanças. Nos dias de hoje, a pesquisa no campo da saúde deve estar voltada para o desenvolvimento e a avaliação de produtos, intervenções e políticas. Estamos falando de um tempo em que a ciência da regulação e a ciência acadêmica se aproximam para favorecer as necessárias transformações.

Temos, portanto, dois modos de fazer ciência. O primeiro é baseado em disciplinas e organizado em torno de um sistema de mérito, com base em publicação acadêmica. E o segundo está voltado para problemas e não restrito a disciplinas específicas, com produtos que não se limitam a publicações - embora, naturalmente, sem excluílas. Esta é a tendência contemporânea: a aproximação cada vez maior das agências de fomento e das agências regulatórias na produção do conhecimento científico, com maior ênfase na investigação de problemas do mundo real.

Quando transpomos essa discussão para o terreno da Saúde Coletiva/Saúde do Idoso, ela assume importância extraordinária. Trata-se de uma área de conhecimento que precisará, cada vez mais, se preocupar com a mudança do "modo de pesquisa", visando produzir, por exemplo, modelos assistenciais mais eficientes, resolutivos, de qualidade superior e custos mais baixos, que possibilitem a inclusão e a redução de riscos. Tudo isto incorporado ao conhecimento das ciências das áreas sociais e econômica - sem ignorar as ciências biológicas -, na busca permanente de excelência e práticas inovadoras.

Estamos vivendo um período de transição. $\mathrm{E}$ as mudanças estão prestes a acontecer. As características peculiares da população idosa - doenças crônicas e mais frequentes, necessidade de amparo familiar ou afetivo, custos crescentes, encargos para familiares e responsáveis impõem que a RBGG assuma seu protagonismo nesse debate e apresente de forma decisiva sua contribuição. 